\title{
OIL PALM-BASED NANOCRYSTALLINE CELLULOSE IN THE EMULSION SYSTEM OF CYCLIC NATURAL RUBBER
}

\author{
I. P. Mahendra ${ }^{1}$, B. Wirjosentono ${ }^{1}$,*, Tamrin ${ }^{1}$, H. Ismail ${ }^{2}$, and J.A. Mendez ${ }^{3}$ \\ ${ }^{1}$ Departemen Kimia, Fakultas Matematika dan Ilmu Pengetahuan Alam, \\ Universitas Sumatera Utara, Medan, Indonesia \\ ${ }^{2}$ School of Material and Mineral Resources Eng. Universiti Sains Malaysia, Penang, Malaysia \\ ${ }^{3}$ EnginyeriaQuímica, Agrària i Tecnologia Agroalimentària, Universitat de Girona, \\ POLITÈCNICA I, Campus Montilivi, 17003-Girona, Spain \\ *E-mail: basuki@usu.ac.id
}

ABSTRACT

The oil palm's nanocrystalline cellulose (NCC) has been successfully isolated and characterized, also it has been applied in the emulsion system of cyclic natural rubber (CNR). Nanocrystalline cellulose (NCC) has been isolated and characterized from the lower part of empty fruit bunches (LEFB) by acid hydrolysis and followed by ultrasonication treatment. The obtained NCC has characteristic, such as (i) the crystallinity index of NCC was $77.84 \%$ and the dimension of NCC was $30-450 \mathrm{~nm}$ and $20-35 \mathrm{~nm}$ of length and width, respectively. The utilization of NCC in the emulsion's system of CNR can improve the stability of the emulsion system that measured by ESI value. The emulsion's system of CNR has divided into two groups based on the type of surfactants, such as Tween 80 and Lutrol F127. In the emulsion that prepared by Tween 80 , at $28^{\text {th }}$ days after the addition of NCC (2-29\% of fibril dosages), the ESI value was in the range 70-100\% and linear with the fibril dosages.

Keywords: Oil Palm, Nanocrystalline Cellulose, Emulsion, Cyclic Natural Rubber, Stability.

(c) RASĀYAN. All rights reserved

\section{INTRODUCTION}

Nanocellulose is one of popular renewable material due to chemical and physical properties, also it can act as nanofiller to improve the material properties, i.e. mechanical and thermal properties ${ }^{1}$. The research that focused on the isolation of nanocellulose, especially NCC gaining much interest with the variation in the isolation processes and raw materials. The NCC production from a waste of oil palm will significantly give benefits to the agricultural and environmental sectors. This innovation can increase the value of oil palm waste by producing valuable products with the impact it will help the environmental issue $^{2}$. NCC can be applied in a wide area of research, such as nanocomposite material, cosmetic, coating, adhesive, membrane, packaging, biomedicine etc. ${ }^{3,4}$. As filler of nanocomposite, NCC has been used in various kind of polymer matrices, such as polypropylene (PP), polyurethane (PU), poly(lactic acid)/polyamide and others ${ }^{5-11}$. The application of NCC as filler is only suitable with hydrophilic polymer and this property make NCC become incompatible with the hydrophobic polymer matrices ${ }^{12}$.

NCC has a rod-like shape with length $100-500 \mathrm{~nm}$ and with crystallinity degree between 50 and $90 \%{ }^{13,14}$. The isolation method to obtain micro or nanocellulose can be classified into chemical (acid and alkaline hydrolyzed), mechanical (ultrasound technique, steam explosion treatment, high-pressure homogenization), and enzymatic isolation processes ${ }^{15-20}$. The properties of NCC that prepared with acid hydrolyzed treatment including, stability and dimension are dependent on the conditions of the reaction and sources of the cellulose ${ }^{21}$. Especially, the NCC prepared by acid hydrolysis, using sulphuric acid, will give a positive impact on the stability of NCC in aqueous suspension and thermal properties ${ }^{12}$.

Cyclized natural rubber (CNR), a derivate of natural rubber or its latex form through cyclization process, has been used in the paint industry, especially as a component to formulate a binder for vessel's paint.

Rasayan J. Chem., 12(2), 635-640(2019)

http://dx.doi.org/10.31788/RJC.2019.1225089

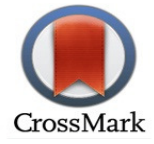


Only a few studies, report about the development of cyclized natural rubber as paint or binder, also about its properties to form an emulsion or waterborne paint. Cellulose and the derivative product of cellulose have been utilized as a stabilizing agent for water-in-oil or oil-in-water emulsion, i.e. bacterial cellulose and its oxidation product, microcrystalline cellulose, modified cellulose using hydrophobic substrate ${ }^{22-27}$. In the previous work, NCC has been applied as a reinforcing agent in the waterborne coating formulation ${ }^{28}$. However, no studies could be found yet on the NCC that isolated from the LEFB and its role to stabilize the emulsion of cyclized natural rubber (CNR). In this work, special attention will be given to the characterization of isolated NCC from LEFB and it influenced the emulsion properties of CNR. The obtained NCC was characterized by FT-IR, TEM, and XRD. The role of NCC in the emulsion properties of CNR was determined from ESI value by visual assessment.

\section{EXPERIMENTAL}

\section{Materials}

The oil palm fiber was obtained from the plantation of oil palm in Riau, Indonesia. The chemicals in this research were analytical grade. $\mathrm{NaOCl}, \mathrm{H}_{2} \mathrm{SO}_{4}$ (95-98wt.\%), $\mathrm{NaOH}$ was purchased from Sigma-Aldrich. The surfactant (Tween80 and Lutrol F127) was obtained from Panreac AppliChem and BASF.

\section{Isolation of Nanocrystalline Cellulose}

The LEFB was cut with a dimension of $1 \mathrm{~cm} \times 1 \mathrm{~cm} \times 1 \mathrm{~cm}$. The LEFB chip was dried in oven for 48 hours and it was ground to a fine powder.

The isolation of NCC was initiated by the isolation of $\alpha$-cellulose ${ }^{29}$. About $75 \mathrm{~g}$ of the LEFB were weighed and soaked with $1 \mathrm{~L}$ of $\mathrm{HNO}_{3} 3.5 \%$ and $10 \mathrm{mg}$ of $\mathrm{NaNO}_{2}$ at $90^{\circ} \mathrm{C}$ for 2 hours. The fibers were filtrated and washed with water up to $\mathrm{pH}$ 7. The following fibers were reacted with $750 \mathrm{~mL}$ of $\mathrm{NaOH} 2 \%$ and $\mathrm{Na}_{2} \mathrm{SO}_{3}$, respectively, at $50^{\circ} \mathrm{C}$ for 1 hour to get the cellulose fibers. The cellulose fibers were bleached with $250 \mathrm{~mL}$ of $\mathrm{NaClO} 1.75 \%$ at $70^{\circ} \mathrm{C}$ for 30 minutes and then washed with deionized water until the washed water was free of chloride ion. After that process, to remove hemicellulose components, the bleached fibers were soaked in $1.75 \%$ of $\mathrm{NaOH}$ solution at $80^{\circ} \mathrm{C}$ for 30 minutes and washed with deionized water until neutral $\mathrm{pH}$ was obtained. The obtained fibers were treated using $\mathrm{H}_{2} \mathrm{O}_{2} 10 \%$ at $60^{\circ} \mathrm{C}$ for 15 minutes and washed with deionized water up to $\mathrm{pH} 7$.

The obtained $\alpha$-cellulose was hydrolyzed using $\mathrm{H}_{2} \mathrm{SO}_{4}(64 \mathrm{wt} . \%)$ solution $(1: 20 \mathrm{w} / \mathrm{w})$ at $45^{\circ} \mathrm{C}$ for $1 \mathrm{~h}$. The obtained precipitate was resuspended in water and centrifuged at $6500 \mathrm{rpm}$ for 20 minutes. The suspension of $\alpha$-cellulose was dialyzed for 7 days. The obtained nanocellulose was homogenized using ultrasonic for 15 minutes.

\section{Preparation of Emulsion System}

The solution of CNR (20wt.\%) was mixed with surfactant and the solution of NCC which has fibril dosage concentration in the range of 2-29 wt.\%. The volume ratio of CNR:NCC: surfactant was 30:30:10. The mixture of CNR was sonicated until it formed a homogenous phase. The stability of emulsion was evaluated from a value that called an emulsion stability index (ESI), which was calculated as Eq. (1):

$$
E S I(\%)=\frac{H E}{H T} \times 100 \%
$$

HE and HT indicated the emulsified layer's height and emulsion's total height, respectively ${ }^{30}$.

\section{Characterization}

The FT-IR spectra of $\alpha$-cellulose and NCC were recorded using FTIR spectrophotometer 8201PC Shimadzu. Microstructural of $\alpha$-cellulose and NCC were characterized using TEM JEOL JEM 1400. Meanwhile, the crystallography of $\alpha$-cellulose and NCC was evaluated using Shimadzu 6100 X-ray diffractometers. The crystallinity index of samples was determined using Segal equation ${ }^{31}$.

\section{RESULTS AND DISCUSSION}

The isolated NCC that obtained from the lower part of empty fruit bunches oil palm has been characterized by several techniques. The spectra of both materials, $\alpha$-cellulose, and NCC, were found to 
be similar. The FT-IR spectra of those materials were dominated by 3500-3300, 2900-2890, 1635, 1370 and $1050 \mathrm{~cm}^{-1}$ signals that referred to the stretching of hydroxyl $(-\mathrm{OH})$, aliphatic saturated $(-\mathrm{C}-\mathrm{H})$, absorbed water, methylene $\left(-\mathrm{CH}_{2}\right)$ and $\mathrm{C}-\mathrm{O}$ from the lignin's unit, respectively. The difference of $\alpha-$ cellulose and NCC spectra can be found in the intensities of the signals. These differences were considered as the result of the oxidation process of the cellulose during the acid hydrolysis treatment.

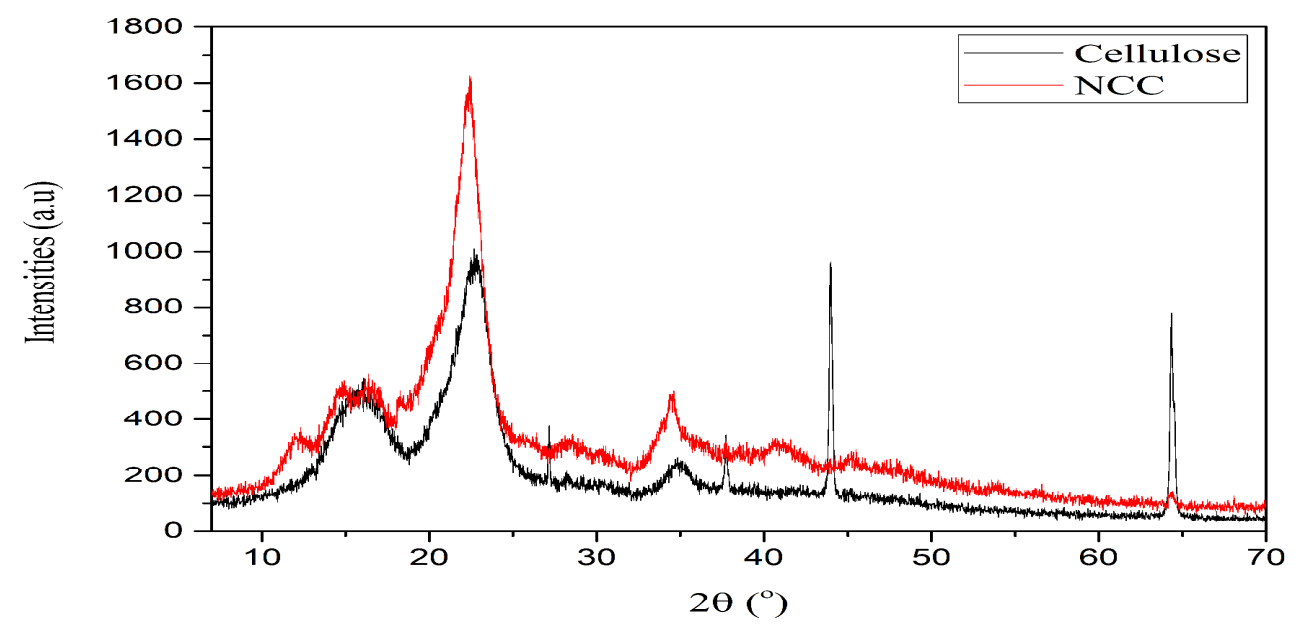

Fig.-1: XRD Spectra of Isolated Cellulose and NCC

The significant difference between the $\alpha$-cellulose and NCC XRD pattern can be observed on their intensities at those $2 \theta$. It was found the NCC showed stronger intensity at $2 \theta 22.5^{\circ}$ compared to $\alpha$ cellulose. A sharp increase of intensity of NCC peak observed at $22.5^{\circ}$ that indicated an increase of crystalline region after hydrolysis treatment (Fig.-1). That statement was supported with the crystalline index of NCC and $\alpha$-cellulose. The crystallinity index of both materials was 73.04 and $77.84 \%$, respectively. This is the impact of hydrolysis treatment during the formation of NCC, the hydrolysis treatment attacks the amorphous regions of cellulose. That penetration causes hydrolytic cleavage of glycosidic bond and releasing of individual crystallites ${ }^{21}$. The thickness of crystallite size that obtained using Scherrer equation was $2 \mathrm{~nm}$. This result was different from the average particle size that obtained using TEM, $10.41 \mathrm{~nm}$. The difference in NCC sized that obtained by TEM and XRD could be caused by Debye thermal broadening.
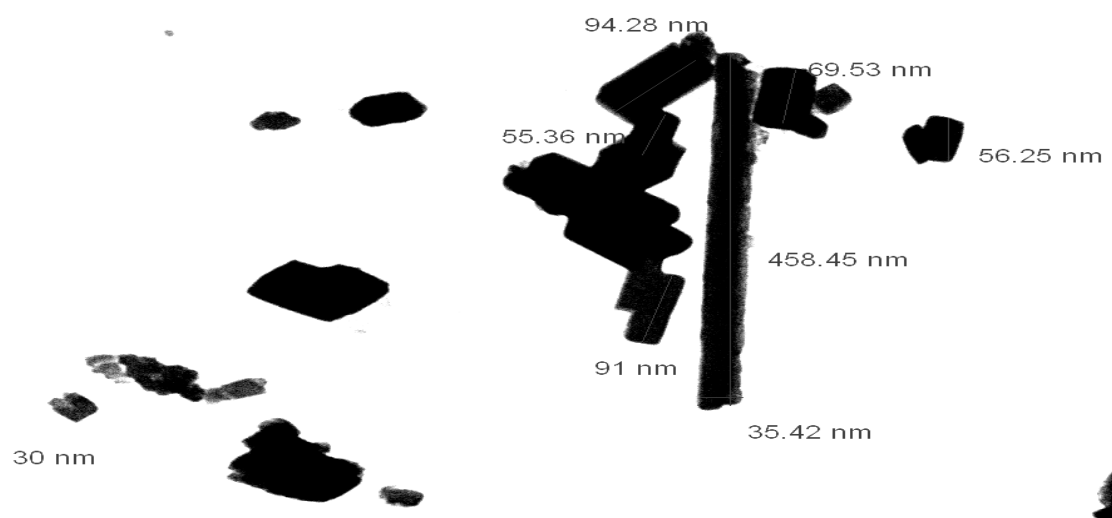

Fig.-2: TEM Image of Isolated NCC

The TEM image of NCC (Fig.-2) was shown as a single rod-shaped and formed aggregates. That aggregate obtained as the result of ultrasonic treatment and the effect of the interaction of hydroxyl group 
on the surface of NCC to form the interfacial hydrogen bonding. NCC rod-shaped that observed using TEM having length $30-458 \mathrm{~nm}$ with a width of the particle was $20-35 \mathrm{~nm}$.
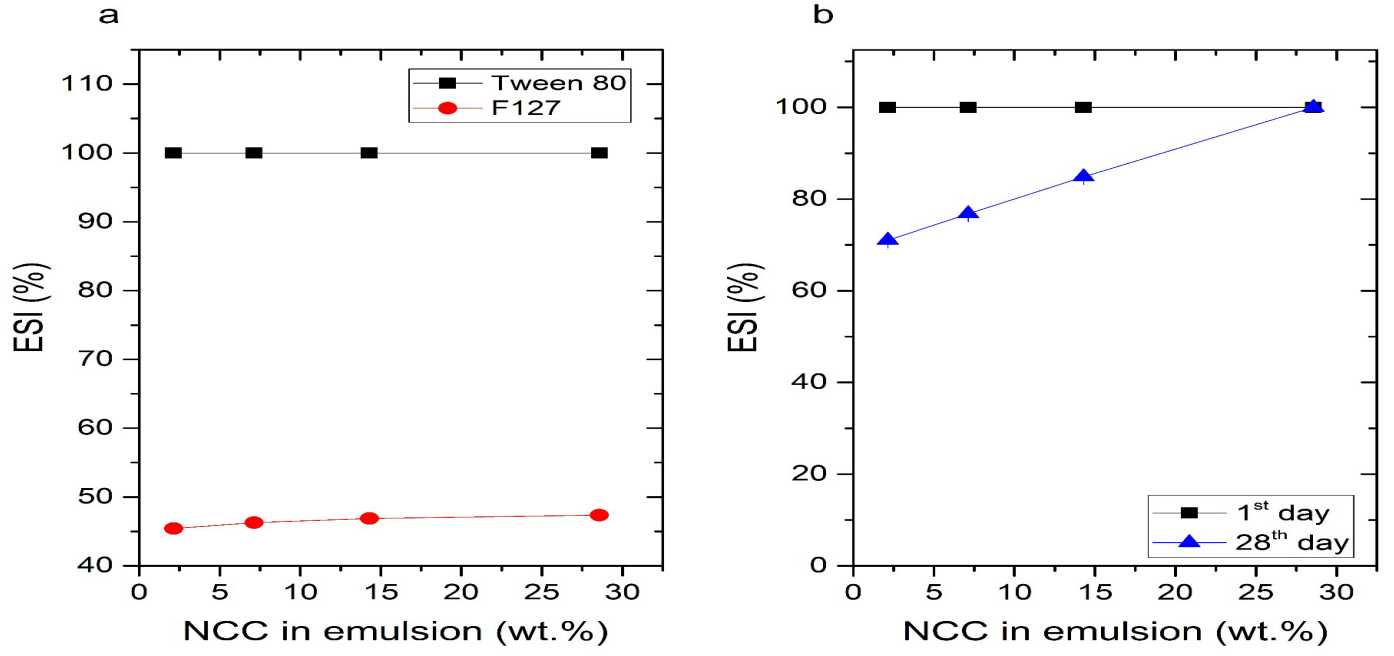

Fig.-3: Relationship between ESI and NCC Dosage in Emulsion

Associations between ESI of emulsions and fibril dosage (2-29 wt.\%.) in the presence of Tween80 and Lutrol F127 are shown in Fig.-3a. For all samples that stabilized using Lutrol F127, stratification occurred upon 15 minutes preparation; then they tended to be stable in $24 \mathrm{~h}$. A different result was obtained in the Tween80-stabilized emulsion. The stratification did not occur in all range of fibril dosage (2-29 wt.\%), with $100 \%$ of ESI ( $\left(1^{\text {st }}\right.$ day), while the ESI of the Lutrol F127-stabilized emulsion was $45.1-47.4 \%$. The emulsion with the present of Tween 80 and Lutrol F127 showed the constant ESI value during three weeks of observation. At the $28^{\text {th }}$ days of visual assessment, the ESI value of Tween80-stabilized emulsion slightly decrease (Fig.-3b), but it showed a trend, the ESI value increased with increasing concentration of NCC.

The influence of fibril dosage in this research is in line with the other results, in the emulsion system of water/paraffin containing TEMPO oxidized bacterial cellulose, the emulsion stability was significantly enhanced with the increasing of fibril dosage ${ }^{32}$. The different result of the emulsion stability at $1^{\text {st }}$ day is directly affected by the type of surfactants. This statement is supported with direct visual assessment, such as in the emulsion system with Lutrol F127 there is white droplet, assumed as surfactant-NCC complex, in the upper part of the solution (Fig.-4). This droplet is not found in the system of CNR/NCC with or without Tween80. Without the presence of Tween80, the solution of CNR and NCC does not mix each other (unstable) over a longer time, NCC is found at the bottom of the chamber. The presence of NCC alone cannot stabilize the oil-water emulsion of CNR. The presence of white droplet in the Lutrol F127®-stabilized emulsion is caused by aggregation or coalescence effect. The coalescence can be occurred by several factors, one of them is insufficient on the surfactant concentration that caused not all of NCC is covered (coated) by the surfactant.

From the ESI result can be concluded, the role of NCC in the emulsion stabilization can be assumed it has a partial contribution to the droplet stabilization or may not have a contribution in the emulsion stabilization. This statement is strengthened by the result of previous work that indicated the presence of NCC in the high concentration of surfactant may not have intermediate wettability needed to stabilize emulsions is likely masked by surfactant. ${ }^{33}$

\section{CONCLUSION}

In summary, the isolated oil palm's NCC has a crystallinity index of $77.84 \%$ and the dimensional of the NCC was $30-450 \mathrm{~cm}$ and $20-35 \mathrm{~nm}$ of length and width, respectively. The emulsion stability that described as ESI showed the addition of NCC into the emulsion system that contained Tween 80 has a higher ESI value than the system contained Lutrol F127 at the same fibril dosage. Focused on emulsion system with Tween 80, after 28 days observation the ESI value was in the range $70-100 \%$ with the 
presence of 2-29\% of fibril dosages. The increase of ESI value showed the trend in increasing of fibril dosages.

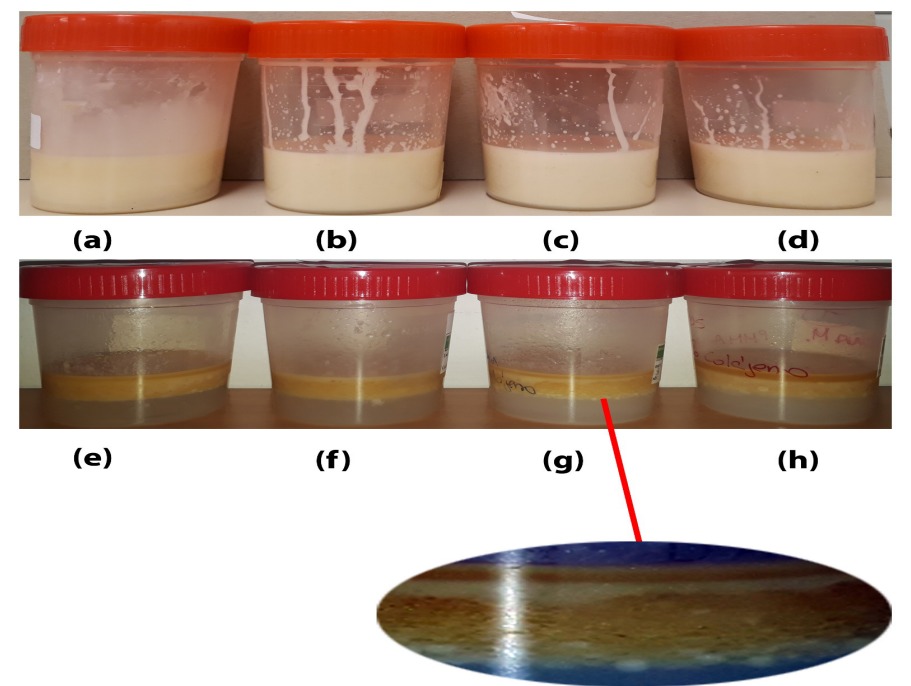

Fig.-4: Emulsion in the Presence of Tween80 (a-d) and Lutrol F127 (e-h) with a difference of NCC Concentration.

\section{ACKNOWLEDGMENT}

The author thanks the Indonesian Ministry of Research, Technology and Higher Education (KEMENRISTEKDIKTI) for the financial support to conduct the research through the PMDSU scholarship program and PKPI PMDSU Batch 2.

\section{REFERENCES}

1. N. Flauzino, W.P. Silvério, H.A. Dantas O., and D.N. Pasquinia, Ind. Crop. Prod., 42, 480(2013), DOI: $10.1016 /$ j.indcrop.2012.06.041

2. J. Lamaming, R. Hashim, O. Sulaiman, C.P. Leh, T. Sugimoto, and N.A. Nordin, Carbohyd. Polym., 127, 202 (2015), DOI: 10.1016/j.carbpol.2015.03.043

3. H.P.S. Abdul Khalil, A.H. Bhat, and A.F. Ireana Yusra, Carbohyd. Polym., 87, 963(2012), DOI: 10.1016/j.carbpol.2011.08.078

4. G. Tuzzin, M. Godinho, A. Dettmer, and A.J. Zattera, Carbohyd. Polym., 148, 69(2016), DOI: 10.1016/j.carbpol.2016.04.045

5. J. Huang and D. Rodrigue, Mater. Des., 65, 974 (2015), DOI: 10.1016/j.matdes.2014.09.081

6. A.I. Cordero, J.I. Amalvy, E. Fortunati, J.M. Kenny, and L.M. Chiacchiarelli, Carbohyd. Polym., 134, 110 (2015), DOI: 10.1016/j.carbpol.2015.07.077

7. V. Heshmati, M.R. Kamal, and B.D. Favis, Eur. Polym. J., 98, 11(2018), DOI: 10.1016/j.eurpolymj.2017.10.027

8. P. Divya, A. Prithiba, and R. Rajalakshmi, Rasayan J. Chem., 12, 214(2019), DOI: 10.31788/RJC.2019.1215039

9. S. Jothibasu, S. Mohanamurugan, and A. Vinod, Rasayan J. Chem., 11, 1255(2018), DOI: $10.31788 /$ RJC.2018.1133096

10. G. Nandhavathy, S. Periyar Selvam, M. Mahesh Kumar, and E. Rotimi Sadiku, Rasayan J. Chem., 10, 542 (2017), DOI:10.7324/RJC.2017.1021724

11. B. Wirjosentono, Tamrin, I.P. Mahendra, D.A. Nasution, H. Ismail, Sukatik, and J.A. Mendez, J. Phys. Conf. Ser., 1120, (2018). DOI: 10.1088/1742-6596/1120/1/012087

12. S. Naduparambath, J. T.V., V. Shaniba, S. M.P., A.K. Balan, and E. Purushothaman, Carbohyd. Polym., 180, 13(2018), DOI: 10.1016/j.carbpol.2017.09.088

13. H.P.S. Abdul Khalil, Y. Davoudpour, M.N. Islam, A. Mustapha, K. Sudesh, R. Dungani, and M. Jawaid, Carbohyd. Polym., 99, 649 (2014), DOI: 10.1016/j.carbpol.2013.08.069 
14. H.P.S. Abdul Khalil, R. Mahayuni, I.U.H. Bhat, D. Rudi, M.Z. Almulali, and C.. Abdullah, BioResources, 7, 5771(2012), DOI: 10.15376/biores.7.4.5771-5780

15. B. Deepa, E. Abraham, B.M. Cherian, A. Bismarck, J.J. Blaker, L.A. Pothan, A.L. Leao, S.F. de Souza, and M. Kottaisamy, Bioresource Technol., 102, 1988(2011), DOI: 10.1016/j.biortech.2010.09.030

16. M. Henriksson, G. Henriksson, L.A. Berglund, and T. Lindström, Eur. Polym. J., 43, 3434(2007), DOI: $10.1016 /$ j.eurpolymj.2007.05.038

17. N. Johar, I. Ahmad, and A. Dufresne, Ind. Crop. Prod., 37, 93(2012), DOI: 10.1016/j.indcrop.2011.12.016

18. J. Li, X. Wei, Q. Wang, J. Chen, G. Chang, L. Kong, J. Su, and Y. Liu, Carbohyd. Polym., 90, 1609(2012), DOI: 10.1016/j.carbpol.2012.07.038

19. W. Li, J. Yue, and S. Liu, Ultrason. Sonochem., 19, 479 (2012), DOI: 10.1016/j.ultsonch.2011.11.007

20. M. Zaman, H. Xiao, F. Chibante, and Y. Ni, Carbohyd. Polym., 89, 163(2012), DOI: 10.1016/j.carbpol.2012.02.066

21. R. Li, J. Fei, Y. Cai, Y. Li, J. Feng, and J. Yao, Carbohyd. Polym., 76, 94(2009), DOI: 10.1016/j.carbpol.2008.09.034

22. M. Andresen and P. Stenius, J. Dispers. Sci. Technol., 28, 837(2007), DOI: 10.1080/01932690701341827

23. J.J. Blaker, K.-Y. Lee, X. Li, A. Menner, and A. Bismarck, Green Chem., 11, 1321(2009), DOI: 10.1039/b913740h

24. I. Capron and B. Cathala, Biomacromolecules, 14, 291(2013), DOI: 10.1021/bm301871k

25. I. Kalashnikova, H. Bizot, P. Bertoncini, B. Cathala, and I. Capron, Soft Matter, 9, 952(2013), DOI: $10.1039 / \mathrm{c} 2 \mathrm{sm} 26472 \mathrm{~b}$

26. H.A. Wege, S. Kim, V.N. Paunov, Q. Zhong, and O.D. Velev, Langmuir, 24, 9245(2008), DOI: $10.1021 / 1 a 801634 j$

27. I.P. Mahendra, B. Wirjosentono, Tamrin, H. Ismail, and J.A. Mendez, AIP Conf. Proc., 2049, (2018). DOI: $10.1063 / 1.5082503$

28. S. Virtanen, S. Jämsä, R. Talja, H. Heikkinen, and S. Vuoti, J. Appl. Polym. Sci., 134, 1(2017), DOI: 10.1002/app.44801

29. F.O. Ohwoavworhua and T.A. Adelakun, Trop. J. Pharm. Res., 4, 501(2007), DOI: 10.4314/tjpr.v4i2.14626

30. T. Winuprasith and M. Suphantharika, Food Hydrocoll., 32, 383(2013), DOI: 10.1016/j.foodhyd.2013.01.023

31. L. Segal, J.J. Creely, A.E. Martin, and C.M. Conrad, Text. Res. J., 29, 786(1959), DOI: 10.1177/004051755902901003

32. Y. Jia, X. Zhai, W. Fu, Y. Liu, F. Li, and C. Zhong, Carbohyd. Polym., 151, 907(2016), DOI: 10.1016/j.carbpol.2016.05.099

33. Z. Hu, S. Ballinger, R. Pelton, and E.D. Cranston, J. Colloid Interf Sci., 439, 139(2015), DOI: 10.1016/J.JCIS.2014.10.034

[RJC-5089/2018] 